Vol.7, No 1. Diciembre de 2015 pp. 1 -29

Artículo original

Recibido para publicación: 13 de octubre de 2015

Aceptado para publicación: 18 de noviembre de 2015

\title{
DERECHOS CORRELACIONALES A LA JUSTICIA TRANSICIONAL VERDAD, JUSTICIA Y REPARACIÓN.
}

\section{Correlational rights to transitional justice, truth, justice and repair}

\author{
Autores: Aura María Echeverría' ${ }^{1}$ (Principal) \\ Estudiantes asistentes: \\ Norelvis Quintana, Johen Albany Escobar Alcaraz, Algiro Anaya, Alba Velez, Alba Rendon
}

Correspondencia: aura.echeverria@curnvirtual.edu.co

\section{RESUMEN}

El presente artículo de investigación busca determinar la eficacia de las leyes que establecen la justicia transicional en Colombia, particularmente en algunos casos ocurridos en el departamento de Bolívar entre los años 1999 y 2001. El interés por investigar obedece a que la aplicación de este tipo de justicia se hace en el período posterior a un conflicto interno en el que han ocurrido violaciones a los derechos humanos, mientras que en el país, no obstante a las transformaciones del fenómeno de la violencia, siguen cometiéndose masivas violaciones a este tipo de derechos, lo que nos lleva a afirmar que nos encontramos aún en una etapa de conflicto. En este artículo se pretendió establecer un marco conceptual en cuanto a lo que se ha definido como justicia transicional y a los derechos correlativos a ella, como son los derechos a la verdad, justicia y a la reparación y a sus tendencias.

\section{Palabras Claves}

justicia transicional, conflicto, eficacia,verdad, justicia, reparación, restitución, postconflicto, víctima, victimario.

\footnotetext{
${ }^{1}$ Docente e Investigadora de la Corporación Universitaria Rafael Núñez, Sede Cartagena, Facultad de Ciencias Sociales y Humanas, Programa de Derecho.
} 


\begin{abstract}
This research paper aims to determine the effectiveness of the laws establishing transitional justice in Colombia, particularly in some cases in the department of Bolivar between 1999 and 2001. The interest in research is because the application of such justice is done in the back of an internal conflict in which human rights violations have occurred period, while in the country, despite the changes in the phenomenon of violence, massive violations continue to be committed to such rights, which leads us to say that we are still in a stage of conflict. This article was intended to establish a conceptual framework in terms of what has been defined as transitional justice and correlative rights to it, such as the rights to truth, justice and reparation and trends.
\end{abstract}

\title{
Keywords
}

transitional justice, conflict, efficiency, truth, justice, reparation, restitution, post-conflict victim, victimizer.

\section{INTRODUCCIÓN}

El presente artículo de investigación científica se desprende de la investigación en ejecución que tiene como Objetivo General "Determinar la eficacia de las leyes que establecen la justicia transicional en Colombia, particularmente en algunos casos ocurridos en el departamento de Bolívar entre los años 1999 y 2001". El interés de desarrollar el citado proyecto de investigación es la situación particular en la que se encuentra Colombia frente la aplicación de este tipo de justicia.

Lo anterior ya que la Justicia Transicional se ha aplicado en períodos donde el conflicto interno o la dictadura en los que han ocurrido graves violaciones a los derechos humanos ya han terminado, mientras que en Colombia, no obstante a las transformaciones del fenómeno de la violencia, siguen cometiéndose masivas violaciones a este tipo de derechos, escenario que nos lleva a afirmar que nos encontramos aún en una etapa de conflicto. 
A pesar de lo narrado No obstante lo dicho, en el país se han hecho esfuerzos por adelantar una transición del conflicto a la paz o por lo menos de respetar los derechos, reconocimiento y el empoderamiento de las víctimas del mismo, actuaciones que pretendemos demostrar haciendo un estudio de la aplicación de las normas de justicia transicional con relación a determinados casos ocurridos en el departamento de Bolívar.

Es por lo descrito que el trabajo consiste en hacer el análisis de la aplicación de las Leyes 975 de 2005, denominada Ley de Justicia y Paz;1424 de 2010 y 1448 de 2011, a las víctimas y victimarios de las masacres ocurridas en los municipios de Macayepo, Manpujan, y el Salao teniendo en cuenta la realidad del país en cuanto a sus actores armados, la verdad que se ha conocido, la capacidad de las instituciones, y en especial las víctimas del conflicto particularmente en los casos citados, que tuvieron ocurrencia en el departamento de Bolívar, porción territorial que ha sido fuertemente azotada por la violencia en décadas, así como, en donde se ha trabajado por la garantía efectiva de los derechos de las víctimas y la no repetición de la violación de los mismos.

Así mismo esta investigación nos permitirá establecer un marco conceptual en cuanto a lo que se ha definido como justicia transicional y a los derechos correlativos a ella, como son los derechos a la verdad, justicia y a la reparación. De igual manera, las tendencias que existen en cuanto a un proceso de transición, las cuales dependen del conflicto mismo, de la sociedad, de las políticas implementadas y de las normas jurídicas que regulen el proceso.

En el presente en el proyecto se tienen en cuenta las experiencias de otros países que han logrado la transición del conflicto a la paz en sus territorios, ya que, estos espacios nos eso nos permiten conocer como ellos han resuelto la tensión entre las obligaciones jurídicas frente a las víctimas, que entre otras son evaluadas por los organismos internacionales, y las necesidades políticas para poder negociar el 
cese del conflicto con los grupos armados que llegaron a participar en él participan en él y de igual manera, determinar que formas han sido eficaces y cuales deben adoptarse para lograrlo, sin olvidar la importancia del en el que se presentan, y especialmente, que Colombia presenta una situación al respecto bastante particular tiene un contexto bastante particular.

El planteamiento del problema del proyecto de investigación hace referencia a ¿Cuál es la eficacia de la aplicación del marco normativo de Justicia Transicional en algunas masacres ocurridas en el departamento de Bolívar entre los años 1999 y 2001 ?

Para poder responder a este planteamiento, el trabajo responde a unos objetivos específicos encaminados a:

a. Exponer la evolución y el estado actual de las discusiones acerca de la Justicia Transicional y de sus conceptos correlaciónales.

b. Conocer la experiencia de países que han implementado Justicia Transicional con ocasión de sus conflictos internos.

c. Establecer los avances que se han presentado en Colombia en relación con los derechos a la verdad, justicia y reparación de las víctimas.

d. Analizar el estado de aplicación de las leyes 975 de 2005, 1424 de 2010 y 1448 de 2011 en el departamento de Bolívar, con ocasión algunos de los hechos atroces ocurridos entre los años de 1999 y 2001.

e. Determinar si en Colombia es viable la aplicación de una Justicia Transicional dado que atraviesa un conflicto interno que no está en etapa de transición.

f. Plantear propuestas relacionadas con la tendencia que sigue Colombia en cuanto a los tipos de Justicia Transicional. 
Vol.7, No 1. Diciembre de 2015 pp. 1 -29

Conociendo los objetivos del proyecto de investigación es necesario hacer una breve exposición de la metodología que se empleará para obtener los resultados y las conclusiones frente a los mismos.

\section{MÉTODOS.}

El tipo de investigación que se va a desarrollar es de carácter aplicado, dado que lo que se pretende es implementar la teoría acerca de Justicia Transicional a los procesos que se adelantan en Colombia con ocasión de las violaciones de los derechos humanos a las poblaciones de sus municipios, particularmente a los del departamento de Bolívar. Con ello se busca determinar si es viable que en Colombia se aplique este tipo de justicia, ya que no se encuentra en la etapa de postconflicto sino que está atravesando el mismo, sin ánimo de cese de acciones violentas.

A este tenor, es aplicada dado que se busca determinar con claridad la clasificación de los tipos de Justicia Transicional y establecer cuál es el que tiene lugar en este país. Para ello es necesario hacer un análisis de la situación teórica como de la experiencia en la aplicación de las normas 975 de 2005, 1242 de 2010 y 1448 de 2011 y exponer el estado actual de las mismas en cuanto a las declaraciones de los victimarios, las sanciones que le han sido aplicadas y de los procesos de reparación y dignificación de las víctima. Lo anterior busca sopesar que tensión se presenta entre esos derechos correlaciónales a la justicia transicional y poder clasificar que tipo es el aplicado en Colombia.

De igual manera, para alcanzar el objetivo general del trabajo se realizará un estudio de casos, en donde se evidencia la metodología de investigación socio jurídica, la cual se desarrollará haciendo recolección de información que permita hacer el estudio intensivo de la situación actual en que se encuentra el trámite 
judicial y social por parte de las instituciones de Estado colombiano para la aplicación de las normas en el caso de algunas de las víctimas de las masacres ocurridas en los municipios de Macayepo, Manpujan, y Salao.

Para hacer el estudio de casos, que es el objeto de la investigación se realizará recolección y análisis de datos correspondientes a diversos puntos de vista 0 posiciones de distintos autores, que además pertenecen a diferentes aéreas del conocimiento, tales como la filosofía, la sociología, la política y el derecho. Lo anterior supone la interdisciplinariedad de la investigación, la cual es necesaria para abordar de la mejor manera el problema de investigación, particularmente el tema de la teorización del concepto de Justicia Transicional, su clasificación y su aplicación en países que atraviesan un conflicto interno.

Por otra parte De otra parte, es una investigación humanista, y por ello de carácter cualitativo, en la que se accederá a un número de víctimas de las violaciones de Derechos Humanos y Derecho Internacional Humanitario en algunos municipios de Bolívar, con el objeto de conocer la experiencias de ellas en relación con la aplicación de las leyes 975 de 2005, 1424 de 2010 y 1448 de 2011. De igual manera conocer la situación en la que se encuentran después de que se les reconocieran sus derechos a ser reparados y restituidos sus territorios.

Esto último con el objeto de determinar si esos territorios han iniciado un tránsito de la guerra a la paz, y en caso negativo, determinar si este tipo de justicia es eficaz en países con un conflicto interno vigente. Para finalmente concluir cual es la tendencia que sigue Colombia en cuanto a los tipos de Justicia Transicional existentes y plantear sugerencias al respecto. 


\section{RESULTADOS Y DISCUSIÓN}

El avance en el proyecto gira en torno a plantear que el conocer la verdad, vista ésta como construcción de la memoria histórica, puede facilitar los procesos de conciencia, colectividad, la sensibilización y el apoyo, hacia las víctimas y así la posibilidad de la reconciliación y de la construcción de paz en Colombia.

En este orden de ideas, el proceso investigativo se propone Lo anterior se propone partiendo de que si en situaciones de conflicto las propuestas de transformación no se hace sobre el presupuesto de conocer la verdad de lo ocurrido, de los hechos, de las víctimas, de los victimarios, del sufrimiento, del dolor, de los muertos, los desaparecidos, las formas y sus crudezas, no es posible saber, sobretodo en un conflicto armado que afecta de una u otra forma lejana o cercana, directa o indirectamente a toda la sociedad, que es lo que se va a reparar, que es lo que se va a perdonar y a olvidar, no se podrá saber si hay justicia o impunidad, si las medidas son excesivas o insuficientes.

Por su parte, en el caso Asimismo, en el caso de Colombia, en donde es tan sonado el tema de la paz, de la firma del acuerdo o de la movilización de algunos, de los marcos legales para el pago de reparaciones, y para el tema de la paz en general, la mayoría de la sociedad en la que ocurrieron los hechos no los conoce, entonces sus juicios, y sus prejuicios están construidos sobre falsas apreciaciones de la realidad o imaginarios que no son construidos con conocimiento de la verdad. Igual que las políticas, las leyes y sus reformas a quien favorecen, los medios de comunicación sobre que informan y en qué forma construyen opinión si no se conocen los hechos.

La temática abordada posee tanta importancia que el proceso de transición que vive Colombia, el cual se da en medio del conflicto, es referente para llegar a 
establecer de qué manera y en qué medida se da la efectividad y eficacia de las etapas surtidas con relación a la Justicia Transicional. Permite además, tener una mirada crítica en el sentido de que si se ha hecho el tránsito o por el contrario las circunstancias conflictivas y la violencia sólo se han convertido en otras formas de tipo negativo o positivo.

Inicialmente, es necesario resaltar que si bien es claro que el conflicto es una constante el vida humana, en el caso Colombiano, parafraseando a Johan Galtung en su texto "Teoría de los conflictos", este ya se transcendió a si mismo convirtiéndose en violencia que llego hasta los límites de la deshumanización absoluta (Galtung 2003). Y con fundamento en lo afirmado por este autor, si no logramos conocer la complejidad del mismo, de sus lógicas, de sus actores, de sus hechos, no podrá ser manejable y transformable. Es por ello que estudiando las teorías acerca de la verdad y sus efectos, la justicia, y la reconciliación desde sus conceptualizaciones y haciendo un ejercicio de estudio de los casos de otros países, en los que la verdad tuvo gran valor, podremos afirmar que tan necesario es conocer la verdad de los hechos, hacer una edificación de la memoria histórica a fin acerarnos a la reconciliación y así a la construcción de la paz.

Si lo que debemos conocer es la complejidad del conflicto, lo primero que debemos tener claro es la complejidad humana, y a lo que ella conlleva en este caso y es en el sinnúmero de historias, verdades que surgen sobre el conflicto, pero tener claro que el objeto es saber que el conocimiento de ellas nos puede llevar hacia la concientización y sensibilización y como consecuencia a la transformación del mismo en la reconciliación y en la reconstrucción de lo que se perdió. Es decir, si bien es cierto que el conflicto colombiano es de más complejo, la posibilidad de transformación pacifica del mismo no será simple, lineal o formal. Pero ofrecemos hacer un análisis de uno de los elementos que bien podría aproximarnos a ello. 
Vol.7, No 1. Diciembre de 2015 pp. 1 -29

La mayoría de los procesos de conformación de organismos internacionales, suscripción de tratados de Derechos Humanos, procesos de construcción de paz y pedagogía social surgen a partir de conocer los hechos ocurridos en la Segunda Guerra Mundial, con ocasión de la llamada "nueva conciencia humanitaria" al no poder aceptar que tantos crímenes fueron cometidos hasta el hecho de que en manos de los humanos podría estar el exterminio de este grupo. Es decir, si al conocer los hechos, las víctimas y los responsables en Colombia se puede despertar la conciencia que nos pueda llevar a la construcción de la paz. De manera tal que si durante tanto tiempo hemos desarrollado una cultura de la violencia, podamos empezar a desarrollar una cultura de paz. El proceso seria, en palabras de Galtung "si quieres paz, prepárate para la paz" en contraposición a la máxima que se sostuvo por muchos años, incluso actualmente "si quieres paz, prepárate para la guerra" (Galtung 2003).

Para desarrollar el planteamiento de que la verdad puede ser el fundamento de la construcción de paz, debemos: i) definir lo que en el presente trabajo se debe entender como verdad, ya que es un concepto con varias acepciones y significados, ii) establecer como se relaciona la divulgación de esa memoria histórica con la construcción de futuro y transformación del conflicto en un contexto de complejidad creciente; iii) Posteriormente, plantear como se puede convertir esta en la base de un proceso de transformación del conflicto. 


\section{Concepto De Verdad Como Memoria Histórica}

En el marco de los conflictos la verdad puede ser entendida de diferentes maneras, entre las que podemos identificar dos, para los fines del presente ensayo, así: 1. La verdad real y, 2. La verdad procesal. En nuestro concepto la primera de ellas está más relacionada con la verdad como proceso de la reconstrucción de los hechos, de una memoria de los relatos que debe conocer la sociedad, a manera de toma de conciencia, que ayude a los procesos de reparación, cicatrización, perdón y reconciliación, y la segunda más relacionada con el derecho a la justicia, a la reducción de la impunidad, a la aplicación de las sanciones. De alguna manera, esta división se caracteriza en las diferencias que existen entre: las comisiones de la verdad y las comisiones extrajudiciales de investigación.

Las comisiones de verdad "son las que responden a la necesidad de esclarecimiento de los hechos de violencia política en contextos de transición" (Ceballos, 2009), y las Comisiones extrajudiciales de investigación "no solo le apuestan al esclarecimiento histórico, sino que por lo general se crean por la urgencia de otorgar impulso a la labor judicial en situaciones de debilidad institucional, son creadas durante el desarrollo del conflicto" (Ceballos, 2009). Definidas estas, podemos afirmar que para nuestro propósito de análisis trabajaremos con las Comisiones de Verdad, sin olvidar que el trabajo de estos dos tipos de comisiones en algún momento del proceso aúnan esfuerzos.

En este mismo sentido, Priscila Hayner señala que existen dos formas de rendir cuentas frente a los crímenes del pasado, una con la aplicación de la ley y otra a través de las Comisiones de la verdad, que para ella están más relacionadas con la investigación y el esclarecimiento que se hace de los hechos, de los patrones 

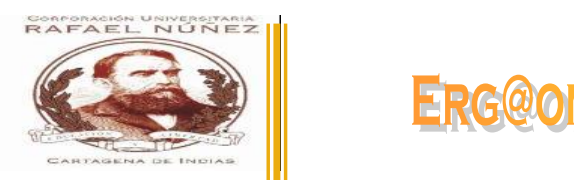

Vol.7, No 1. Diciembre de 2015 pp. 1 -29

de abuso en el pasado (Hayner 2008). Dentro de las características de las

Comisiones de la verdad encontramos las siguientes:

1) Se centran en el pasado; 2) investigan un patrón de abusos cometidos a lo largo de un período, en vez de un suceso concreto; 3) son un organismo temporal, que en lo general funciona durante seis meses a dos años y termina su labor presentando un informe, y 4) tienen el aval, la autorización y el poder oficial que les concede el Estado (y a veces también la oposición armada, como sucede tras un acuerdo de paz). Este carácter oficial concede a las comisiones de la verdad un mejor acceso a las fuentes de información oficial, más seguridad para llevar a cabo investigaciones delicadas y más posibilidades de que las autoridades tomen en serio su informe y sus recomendaciones. (Hayner 2008: 41).

De otra parte, estas características nos llevan a conseguir unos objetivos claros dentro de los que se encuentran, hacer una reconstrucción de los hechos, de los patrones de violencias, los actores, resaltando que la pretensión principal es la de clarificar, conocer los hechos y reconocer los abusos, las violaciones de derechos que ocurrieron en el pasado. Esto se hace con la intensión de responder a las necesidades de las víctimas, si se puede contribuir a la justicia, y que exista un reconocimiento de responsabilidad de la instituciones y de los grupos armados. Partiendo de esto, las Comisiones de la Verdad hacen recomendaciones en cuanto a las reformas que debe hacer el Estado y lo más importante a partir de este ejercicio se aliente la reconciliación y la reducción de los conflictos en torno al pasado.

En palabras de la autora los resultados de las Comisiones de verdad permiten: 
Vol.7, No 1. Diciembre de 2015 pp. 1 -29

Conocer los crímenes y crear un ambiente propicio para una reconciliación nacional. Asimismo, los informes generados tienen un gran valor histórico, ya que permiten conocer, por un lado, los crímenes con todas sus atrocidades, saber quiénes los cometieron y calcular el número de víctimas; por el otro, pueden ser utilizados en los tribunales internacionales con la finalidad de castigar los crímenes de lesa humanidad. (Hayner 2008: 54).

De esto se desprende además el carácter reparador, restaurador y simbólico que tiene la verdad, entre los cuales se dan los episodios de arrepentimiento y perdón entre las víctimas y los victimarios. Que consideramos necesarios para iniciar el proceso de reconciliación nacional propio de las etapas de justicia transicional, que tienen como la instalación de la paz y la convivencia armónica.

Lo dicho en párrafos anteriores es claros, pero ello consideramos necesario que el resultado del proceso de recuperación de los hechos y de las verdades sea conocido por toda la sociedad, obedeciendo el hecho de que la reconciliación es de carácter nacional, y a que los efectos de los proceso recaen y ocurren sobre toda ella y en mucho el desarrollo y eficacia de los proceso depende de la conciencia que tengan todos los miembros de la comunidad sobre los mismos.

El concepto de verdad, en el contexto en que lo estamos aplicando, tiene múltiples acepciones tal como ya lo señalamos, de igual manera no solo en Colombia este ha generado un gran debate, entre diferentes autores y en los organismos de los sistemas de protección de Derechos Humanos, como por ejemplo: la Comisión Interamericana de Derechos Humanos (CIDH). Esta última inicialmente consideró que el derecho a la verdad se trataba de la posibilidad de que las familias conocieran la suerte de sus seres queridos, derivado de la obligación que tienen los Estados de brindar a las víctimas o sus familiares un 
Vol.7, No 1. Diciembre de 2015 pp. 1 -29

recurso sencillo y rápido que los ampare contra violaciones de sus derechos fundamentales.

Posteriormente la interpretación ha evolucionado y en algunas peticiones presentadas con ocasión de la amnistía a los hechos en la dictadura chilena, la CIDH manifestó que:

El derecho a la verdad pertenece a las víctimas y sus familiares y también a la sociedad en general, ya que cuando se dictan amnistías, los Estados deben adoptar las medidas necesarias para establecer los hechos e identificar a los responsables. Y así toda sociedad tiene el derecho inalienable de conocer la verdad de lo ocurrido, así como las razones y circunstancias en las que aberrantes delitos llegaron a cometerse, a fin de evitar que esos hechos vuelvan a ocurrir en el futuro. (CIDH, 2000)

En este marco De otra parte, la Organización de las Naciones Unidas ha manifestado que:

Cada pueblo tiene el derecho inalienable a conocer la verdad sobre los acontecimientos sucedidos en el pasado, en relación con la perpetración de crímenes aberrantes y de las circunstancias y de los motivos que llevaron, mediante violaciones masivas o sistemáticas, a la perpetración de estos crímenes. El ejercicio pleno y efectivo del derecho a la verdad, proporciona una salvaguarda fundamental contra la repetición de éste tipo de violaciones. (ONU)

Estas conceptualizaciones además de plantear el hecho de que la sociedad tiene el derecho a conocer lo ocurrido, también plantea la verdad como ejercicio para posibilitar la transformación del conflicto, en el caso de que al conocer lo 
Vol.7, No 1. Diciembre de 2015 pp. 1 -29

ocurrido, esto de tal manera que sea viable el que no se vuelvan a repetir los mismos hechos. En concepto de los organismos internacionales, la verdad no es solo un derecho sino una medida de satisfacción y de garantía de no repetición si cumple con algunos estándares, así:

(...) entre los que cabe destacar la verificación de los hechos y la difusión pública y completa de la verdad, la búsqueda de las personas desaparecidas y de los cadáveres de las personas muertas, las disculpas públicas que reconozcan los hechos y acepten las responsabilidades, la aplicación de sanciones judiciales o administrativas a los responsables y las conmemoraciones y homenajes a las víctimas. (Botero 2006: 75).

En conclusión, el conocimiento de los hechos, y el reconocimiento de las atrocidades cometidas, los motivos y las circunstancias nos llevan a que el colectivo completo, es decir la "(...) La sociedad tiene el derecho a conocer la verdad en cuanto a tales crímenes con el propósito de que tenga capacidad de prevenirlos en el futuro" (Corte IDH, 2002, párr. 77. Corte IDH, 2002a, párr. 114; Corte IDH, 2003,párr. 274).

Este derecho que debe ser de la sociedad completa, especialmente para facilitar los procesos de transición, se materializan como es función de las Comisiones de la Verdad, en la reconstrucción de la historia, en la que se expone la forma en que la sociedad narra el pasado y su relación con él, su visión del mismo. En palabras de Siegel:

[m] uchos de nuestros entendimientos sociales constitutivos asumen forma narrativa y, muchas veces, estas narrativas incluyen historias acerca del pasado. Al contar historias acerca de un pasado común, un grupo se constituye a sí mismo como grupo, como sujeto 


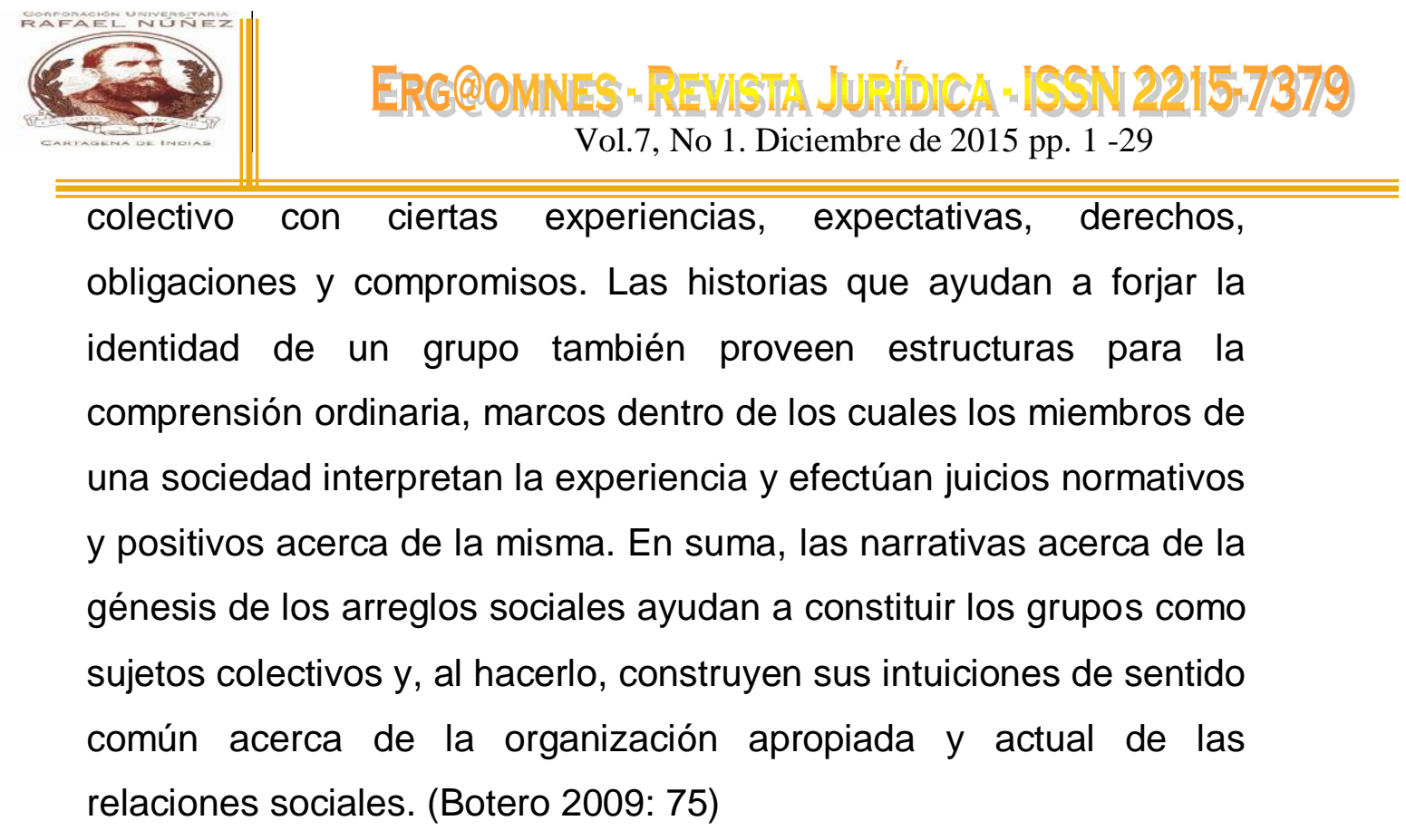

Si se considera la necesidad de sanar las heridas del pasado para alcanzar una convivencia pacífica y un nuevo pacto social para avanzar hacia la reconciliación nacional, estos procesos de reconstrucción del pasado y de publicidad del pasado atroz, adquieren incluso una fuerza histórica esencial. Más aun cuando gran parte de esa cicatrización depende del conocimiento de las víctimas y de la sociedad en general de lo ocurrido, de la efectiva y más completa reconstrucción.

Al establecer esto, estamos afirmando que de esta verdad hacen parte todos los actores del conflicto, los visibles y los no visibles y entonces es necesario plantear la discusión de quien cuenta la verdad real, ya que la judicial depende de un procedimiento y unos actores determinados con un marco de acción limitado por las pruebas.

Al analizar quien cuenta la verdad para la recuperación de la memoria histórica, vemos que estas son tantas como actores hay en el conflicto, no solo los vencedores del mismo, o los de las víctimas directas o de los victimarios, se deben recoger todas, ya que lo que se quiere adquirir es un conocimiento más profundo de las visiones, las perspectivas, los recuerdos. Incluso se quiere conocer lo trascendental del conflicto, la crueldad de los hechos. Al hablar de perspectivas 
deben además tenerse en cuenta las perspectivas de género, ya que la intensión es identificar esas prácticas y patrones de conductas que generan más repudio y condena con el objeto de aportar elementos específicos a la construcción de propuestas de paz, que permitan la cicatrización y la reconciliación.

Con lo expuesto hasta el momento podemos afirmar que la verdad en el marco de la recuperación de la memoria histórica, está conformada por el recuento de varias memorias individuales, de cada uno de los actores como sujetos, memorias sociales, ya que estos sujetos pertenecen a grupos, y el componente del pasado, memoria histórica. Lo anterior evidencia no solo la gran carga de subjetividad que tiene esta reconstrucción de la verdad, sino el alto grado de complejidad que se evidencia en ella, por tanto, debe ser trabajada con esta perspectiva, frente a la cual afirmamos es una forma de asumir la vida y en particular los fenómenos sociales.

Finalmente, para concluir este acápite del documento citamos lo sostenido por Leslie Sequeira, en su dossier sobre la recuperación de la memoria histórica y sus dilemas, "recordar el pasado no significa no haberlo superado, ni seguir viviendo en él, sino que el no olvido incluiríamos el conocimiento de lo ocurrido, sirvan para motivar la convivencia y la paz, fortalecer la democracia, luchar, promover y defender los derechos humanos; debe recordarse que recuperar la memoria histórica es una cuestión de derechos humanos". (Sequeira 2009).

\section{Complejidad Y Verdad: Divulgación Y Construcción De Futuro}

En este acápite, evidenciamos que la complejidad del conflicto, particularmente del colombiano, debido al largo período y espacio del mismo, por el sinnúmero de actores y etapas que ha atravesado, hace necesario esbozar que al plantear 
alguna forma de abordarlo debe plantearse desde la perspectiva de la complejidad.

Entendida la complejidad como una forma de vida que va de concebir el problema, los fenómenos, hasta las soluciones con una visión que vaya más allá de la mirada y explicaciones que la ciencia "normal" ha perpetuado en términos de comportamiento físico, de leyes, de control, para verlas como, fenómenos y problemas de complejidad creciente que necesitan ser abordados por disciplinas, métodos, teorías y en especial lenguajes nuevos que ven la vida como un proceso inacabado que siempre está en movimiento e indeterminación. (Maldonado, 2012)

Estos fenómenos, comportamientos y sistemas no pueden ser entendidos con las herramientas tradicionales, ya que responden a una lógica diferente a la lógica formal y a la del sentido común. Lo que nos lleva a la comprensión de fenómenos, en este caso el conflicto armado colombiano y sus alternativas de transformación, desde la lógica de la no linealidad, lógica binaria, desde el cruce, el dialogo, la cooperación y disciplinas diferentes.

Para poder comprender fenómenos de este tipo debemos tener claro que dentro de los objetos y fenómenos complejos, la vida es el de mayor complejidad, parafraseando a Estanislao Zuleta (Zuleta, 1969), esto se debe a que el ser humano en lugar de desear relaciones inquietantes, complejas y perdibles, que estimulen nuestra capacidad de luchar y nos obliguen a cambiar, deseamos un idilio sin sombras y sin peligros, un nido de amor, y por lo tanto, en última instancia un regreso al huevo. Por ello, no al querer construir este tipo de relaciones, olvidamos o no aprendemos a abordar las situaciones altamente complejas, como es la situación del conflicto colombiano, y pretendemos resolverlo o solucionarlo con planteamientos simples o simplemente reducimos todo a entre menos conozcamos o sepamos mejor, ya que así no nos afecta lo que ocurre y podemos estar tranquilos. 
De igual manera, en aras de lo complejo de la situación en Colombia podemos afirmar que tanto el conflicto como sus hechos y las miradas acerca el mismo está en movimiento y construcción permanente, no se conducen por la línea del tiempo lineal, sino que a medida que avanzamos estas cambian, existen nuevos sentimientos, otras visiones. Así las posibilidades de mirar lo que ha ocurrido y las formas de transformarlo dependen de que podamos aceptar que la complejidad que entraña el contexto lo hará siempre en algún modo indeterminado e incompleto, ya que no obedece a una única lógica, ya que si así fuera estaríamos dejando de lado una cantidad de matices y de posibilidades que son igualmente valiosas.

En este contexto Con base en esto podemos afirmar que el concepto de verdad que trabajamos en el presente texto es un concepto de verdad como una noción relativa a un mundo posible, es decir, depende de las posibilidades, de los grados, de los matices, de las contradicciones y vacíos que se presenten en ese mundo, tanto del que está narrando como del que está haciendo las funciones de receptor, que para el caso es la sociedad.

Para poder acercarnos a las construcciones de verdad, paz, pedagogía social, planteamos hacerlo desde la complejidad particularmente, de acuerdo con el profesor Maldonado (2012), desde el tema de la racionalidad colectiva y de acción colectiva, en la que el colectivo actúa como un organismo y no de una suma de individuos. Es decir, debemos como sociedad comprendernos como un sujeto social, que tiene una vida, espacios de deliberación y acción colectiva de la que debe beneficiarse el organismo colectivo y no el individuo, negando así la posibilidad del egoísmo del individualismo.

En suma lo que esbozamos nos lleva inicialmente a tener conocimiento de lo ocurrido, de la historia del conflicto y del conflicto mismo, de sus actores con sus 
visiones, sus razones, las consecuencias, ya que de ahí debemos partir para poder asumir como colectivo, y en consecuencia poder actuar como colectivo, como organismo.

Es de significar que En esto radica el argumento central del presente trabajo y es que para poder conocer, tener conciencia del colectivo del que hacemos parte, debemos conocer la verdad de lo ocurrido, y esto depende de la reconstrucción que se haga y de la divulgación de la misma como memoria histórica, construida con el mayor número de subjetividades posibles, como base para poder tener un imaginario colectivo que será la base de lo que hemos sido y que nos marcará lo que podemos ser, lo que queremos ser, lo que queremos construir y las posibilidades para llegar a ello.

Solo si conocemos podremos garantizar que la sociedad, en términos de imaginarios colectivos, puede generar nuevos lenguajes para designar una nueva concepción del mundo, de país, de sociedad. Es decir, para poder lograr el país transformado debemos hacerlo a través de la imaginación colectiva, ya que esta tiene una función creadora que debe empezar por la deconstrucción o reinvención del "mundo" individual al de organismo. Y para esto no se puede más que generar una conciencia colectiva de lo ocurrido, de lo que no queremos que vuelva a ocurrir y de lo que queremos conseguir.

Así, desde los planteamientos de las ciencias de la complejidad, es el lenguaje el primer objeto que permite la existencia de los colectivos y organizaciones sociales, ya que es este el encargado de generar diálogos, acuerdos, el sentido y las formas de interacción entre los miembros de la organización. Es el lenguaje el que da la posibilidad de que el discurso del colectivo sea inclusivo o exclusivo, es alrededor de él que se genera disenso o consenso, por tanto, es el lenguaje el elemento que permite que la articulación de los sujetos pueda hacerse de una manera distinta a la tradicional, para lo que es necesario uno nuevo. 
Y esa manera tradicional o histórica, solo la podemos conocer y tener conciencia de ella a través de las narraciones de los actores visibles e invisibles del conflicto, lo que nos va a permitir conocer cuál es el lenguaje que vamos a deconstruir y a partir de allí construir uno. En caso de no hacerlo estaríamos consolidando y perpetuando la realidad existente, en palabras de diferentes autores, se estaría normalizando las formas de violencia que se presentan en el conflicto colombiano. Cosa que ha venido ocurriendo y que por desconocimiento permitimos y reproducimos la violencia directa, estructural y la hemos convertido en violencia cultural.

En su texto Alejandro Peñuela (2009) señala que: "Pero solo en el acto del análisis, de la verbalización, el sujeto representa, recrea, asigna imágenes, valores simbólicos a lo que se encuentra dentro de su campo de percepción en función de su historia como un sujeto in-formado". De igual manera, y en forma más contundente, el profesor Gabriel Vélez Cuartas plantea porque el lenguaje es el objeto más importante si queremos generar nuevas formas de relaciones sociales de la siguiente manera: "Las relaciones sociales desde este punto de vista, sólo pueden ser explicadas a partir del sentido construido por los sujetos, reflejado en sus expresiones lingüísticas". (Vélez 2011)

Como se ha mencionado y para poder aplicar esa mirada desde la complejidad, se propone construir desde ella tanto la memoria histórica del conflicto, como las alternativas de transformación del mismo y ello solo es posible lograrlo desde el conocimiento que debe que tener la sociedad, como derecho y como obligación, de lo que ha ocurrido en su territorio desde hace más de cinco décadas con una crueldad, terror y crudeza cada vez más creciente.

De acuerdo con lo anterior, la conciencia de la realidad es lo que le puede permitir a la sociedad colombiana ser partícipe de nuevas dinámicas sociales, culturales y 
de vida que modifiquen las relaciones, las identidades, y las prácticas sociales violentas actuales. Pero incluso para saber que son nuevas, debe saber qué y cómo el conflicto, que se ha encargado de fijar formas de vida, imaginarios de los habitantes, de las organizaciones, y un lenguaje, para toda la sociedad colombiana, conocer cuáles son. $\mathrm{Y}$ desde estas iniciar con el proceso de un cambio de la cultura "si quieres paz prepárate para la paz" generando una ruptura en la comprensión de la realidad colombiana y así la transformación de las relaciones sociales que ha fijado el conflicto.

El ejercicio de conocer y tener conciencia de la historia del conflicto en Colombia nos debe llevar al sentimiento de solidaridad, que permita crear proyectos comunes, en los que el beneficio de los individuos sea valorado por el beneficio que aportó a la colectividad, de tal forma que podamos alcanzar el objetivo de un proceso de justicia transicional, que es la transformación del conflicto para alcanzar la paz y la armonía en la sociedad.

El proceso de concientización nos puede llevar a la construcción de posibilidades de transformación del conflicto desde una mirada plural, el cambio del lenguajes de las representaciones, de los imaginarios de los actores, del pasado y de los futuros vistos desde las múltiples miradas, múltiples posibilidades de paz y de esta última vista como, dentro de las muchas definiciones paz, como "ayuda mutua para el desarrollo" planteado por Kropotkim en su texto Mutual Aid, citado johan Galtung (Galtung 2003)

Atendiendo a que esta definición encaja perfectamente en la mirada compleja del tema del conflicto y de la paz, en ella no se describe que es el desarrollo, lo que hace posible que sea definido por el antidestino (Núñez. 2007). 


\section{Proceso De Transformación Del Conflicto Desde La Base Del Conocimiento En El Contexto Colombiano}

\section{Transcendencia y transformación del conflicto en Galtung}

Luego de haber planteado que es necesario tener conocimiento de los hechos ocurridos, a través de la reconstrucción de la memoria histórica y de su divulgación, para producir la conciencia y sensibilización de la sociedad en general, y como a partir de esto se puede iniciar un proceso de transformación del conflicto a través de los cambio de lenguaje y representaciones de la colectividad, de los imaginarios colectivos actuales y promoviendo los futuros; proponemos en este último acápite la forma como esto se puede convertir en la base de un proceso pedagógico de cultura de paz.

Es así como, a partir de lo dicho acerca de la construcción de la memoria histórica, en relación con el derecho a la verdad, lo complejo de este proceso y los beneficios de que la sociedad conozca lo ocurrido nos permite afianzar una propuesta de Johan Galtung, en particular su método Trancend, el cual propone como elementos básicos:

- Superar el conflicto con la finalidad de que todas las partes alcancen sus objetivos. Hacer, crear las condiciones para que los aspectos transformativos sean dominantes.

- Observa el dialogo como el método más adecuado para llevar a cabo esta acción. Diálogos transformativos.

- Empatía, creatividad y no violencia.

- Considera a los actores como partes iguales. La transformación va más allá de las asimetrías sociales. 
- Supone el conocimiento de todas las circunstancias que rodean al conflicto, así como los orígenes de la violencia.

- Supone la presencia de una tercera persona, el trabajador de la paz, que actúe como fundamentalmente como moderador entre las partes implicadas.

- Implica las nociones de las 3R (Reconciliación, Reconstrucción, Resolución).

- Implica los niveles micro, meso, macro y mega.

- Tiene como sus elementos metodológicos: no violencia, creatividad y empatía.

- Tiene incorporado el principio no violento de la reversibilidad. (Galtung 2003: 80)

Citados los elementos de la propuesta de Galtung, vemos que el los plantea como una forma de transcender y transformar los conflictos, y por ello entiende que deben darse los proceso de: reconstrucción, reconciliación y resolución de los mismos, no como la construcción de algo nuevo, sino como hacer resurgir las habilidades olvidadas por el conflicto.

Ante el mencionado panorama Con esto, la sociedad debe buscar las formas de superar los traumas, los hechos de violencia y sus orígenes, proponiéndose metas comunes a la colectividad. Esas metas solo pueden establecerse a partir de conocer los límites que impuso el conflicto, y del dialogo entre los actores del mismo y de la sociedad en general, pero que deben empezarse por experiencias micro, por grupos que inicien con la transformación de lo ocurrido, esas experiencias deben divulgarse, ya que eso ira modificando la realidad, y serán nuevos imaginarios en el colectivo.

Para Galtung transcender el conflicto es ir más allá de él, más allá de sus fundamentos, los cuales fueron conocidos a través del diálogo. 


\section{Colombia y la posibilidad de transformación del conflicto}

En el caso colombiano se hace necesario que todos los asociados conozcamos los hechos y los actores, particularmente el sufrimiento y las consecuencias de los hechos deshumanizados vividos, ya que en este momento nos encontramos atravesando una etapa de transición y la gran mayoría de la sociedad no conoce los niveles de crueldad, la magnitud de la violencia que se ha vivido y se vive aún en diferentes zonas del país. No se tiene conciencia de las necesidades ni de las carencias en la que se encuentra esa gran parte de la sociedad.

Este hecho imposibilita que proyectos de reconciliación, de reconstrucción del tejido social sean viables, y en muchos caso, particularmente en la situación de los desplazados y despojados sea un factor revictimizante mas de los ya sufridos.

En Colombia hay proyectos legislativos, existe un marco legal de la justicia transicional, que busca garantizar los derechos a la verdad, justicia y reparación de las víctimas. Alrededor del cumplimiento de estos derechos y en marco de algunos de los procesos contra uno de los actores armados de conflicto se han conocido algunas declaraciones, que han sido presentados públicamente, de igual manera en el marco de estos algunas muy pocas víctimas han dado a conocer su testimonio de los hechos.

De igual manera, se han creado instancias como la Comisión Nacional de Reparación y Reconciliación - CNRR y el Centro Nacional de Memoria Histórica, que han generado unos valiosísimos documentos que reconstruyen los hechos ocurridos en unas zonas del país. 
Vol.7, No 1. Diciembre de 2015 pp. 1 -29

En este caso, y solo a manera de crítica constructiva se han dejado por fuera algunos autores valiosos en el contexto en que se desenvolvieron los hechos y en el caso de las recomendaciones que en algunos de los casos se hicieron.

Como se ha advertido anteriormente No obstante lo anterior, estos esfuerzos no han sido conocidos masivamente o por una gran parte de la sociedad. La situación de conflicto en Colombia se ha extendido por más de cinco décadas y ha afectado la totalidad del territorio nacional, encontramos víctimas y victimarios tanto en las zonas rurales como urbanas, incluso en el Congreso de la República y en diferentes entidades y realmente son escasos los ciudadanos que conocen los hechos, y las razones que dieron origen al mismo. Esto nos lleva a generar un clima de transición, reparación, y sobretodo de reconciliación en el país bastante reducido.

Si bien es cierto que los textos se han publicado y se han hecho eventos de publicidad, estos no han sido suficientes, todavía en el mundo cotidiano cuando algún medio de comunicación, que no han cumplido tampoco con su papel, deja conocer un hecho de la deshumanización y degradación del conflicto es como si ocurriera en otro lugar y no en nuestro propio territorio. El clima de desconocimiento del conflicto ha producido también una apatía frente al mismo y no queremos ver ni saber los alcances. En un ambiente de polarización y estigmatización todo el que habla del tema pertenece a alguna de las extremas fuerzas políticas o ideológicas del país como si eso no nos estuviera ocurriendo como sociedad.

A la par de las anteriores acciones se ha Lo anterior ha originado una percepción y unas representaciones e imaginarios que son poco positivos frente a algunos procesos o mecanismos de tratamiento del conflicto por ejemplo los prejuicios que suscitan las sumas que se pagan de indemnizaciones a las víctimas, la incomodidad que nos generan los desplazados en las calles, la aplicación de pago 
de impuestos a la reparación de las víctimas, los programas de reinsertados, por no hablar de las consecuencias que estas situaciones traen a las ciudades, como las invasiones, las manifestaciones, violencia de las bandas criminales, inseguridad, pandillas, entre muchas otras, de las que se desconocen sus orígenes y su relación con el desconocido conflicto interno.

La falta de conocimiento de lo ocurrido, en sentido contrario a lo afirmado en este documento, trae la falta de concientización, de empatía y sobretodo de solidaridad, lo que desde las dimensiones micro a las macro no son positivas para una construcción de paz, ni mucho menos para una transformación afirmativa del conflicto.

Significamos igualmente que Asimismo, no se conoce lo ocurrido, no se tiene conciencia de ello, muchos ciudadanos no saben que nos encontramos en un proceso de transición (aunque esto no sea del todo claro en medio del conflicto), ni que esto se traduce en unas garantías tanto para las víctimas como para los victimarios en aras de lograr la armonía y la reconciliación nacional. Lo que es aún más delicado, el personal que trabaja directamente con este proceso, no tiene conocimiento de lo ocurrido, no sabe lo que trae consigo una víctima, y son los operadores de los mecanismos que propenden por esa transición.

Esto hace que en Colombia no se viva el proceso de paso de superación de los hechos de violaciones de derechos humanos, porque no tenemos conciencia de que todos hacemos parte de ese proceso, existe tal falta de conocimiento y de ganas de conocer que nos mantenemos al margen de lo que ocurre, nos encontramos indolentes y apáticos a mirar que es lo que ha ocurrido y a aportar como colectivo social a esa reconstrucción de país. Bien sea porque a mí no me paso, por miedo a ser estigmatizado, porque no me identifico con la realidad que viven algunos, consideramos que el hecho de que se firmen leyes y se hagan marchas son suficientes para superar la historia violenta. 
Por ello es que en nuestra opinión solo hasta que se haga una reconstrucción de la memoria que muestre la verdad de lo ocurrido que esta sea pública a través de los medios de comunicación, de las escuelas, las universidades, los organismos encargados de esta función, no será posible obtener un clima propicio para la generación de relaciones sociales nuevas que alienten un sentido de sensibilidad social para con la transformación del conflicto.

Hasta que no seamos conscientes de lo que hemos vivido como colectividad, como organismo social y sigamos en el individualismo egoísta en el que muchos se encuentran, no será posible generar unas nuevas dinámicas sociales, culturales y de vida que modifiquen las relaciones, los imaginarios y esas mismas prácticas sociales violentas en las que nos encontramos y que se han arraigado en la cultura colombiana.

\section{CONCLUSIONES}

En conclusión, debemos conocer el conflicto, sus patrones, sus orígenes y sus consecuencias, para poder deconstruir y reconstruir las formas de vida que él ha fijado, planteando un nuevo lenguaje que nos permita denominar esa nueva forma de vida e iniciar procesos de cambio que sean positivos a una cultura de paz.

Así las cosas, Por ello afirmamos que todo el proceso debe ser público en cumplimiento del derecho y la obligación que tiene la sociedad de conocer lo ocurrido, para saber qué es lo que va a superar, a perdonar, a reconstruir, saber qué fue lo que se perdió y lo más importante de todo que es lo que quiere, hacia donde va y que es lo que no va a permitir que vuelva a ocurrir. 
Vol.7, No 1. Diciembre de 2015 pp. 1 -29

Para trabajar de manera no violenta el conflicto y pueda hacerse propuestas que den resultados, solo con base en el conocimiento de los hechos podemos establecer los objetivos a los que queremos llegar y crear las condiciones de transformación de la realidad. Adicionalmente el principio de estos proceso en palabras de varios autores es el dialogo de todos los actores del conflicto, tanto visibles como no visibles, es básico saber sobre que se dialoga, sobre que se construye.

\section{REFERENCIAS.}

Botero, Catalina. Uprinmy, Rodrigo. Saffon, Maria Paula. Restrepo, Esteban (2006). ¿Justicia transicional sin transición? Verdad, justicia y reparación para Colombia. Bogotá. Antropos.

Ceballos, Marcela (2009). Comisiones de la verdad Guatemala, El Salvador y Sudáfrica, perspectivas para Colombia. Bogotá. La Carreta.

Comisión Interamericana de Derechos Humanos (2000). Monseñor Óscar Arnulfo Romero y Galdámez v. El Salvador. Caso No. 11.481. Informe No. 37/00.

Corte IDH (2002). Caso Bámaca Velásquez. Reparaciones. Sentencia de febrero 22 de 2002. Serie C No. 91.

Corte IDH (2002a). Caso Trujillo Oroza. Reparaciones. Sentencia de febrero 27 de 2002. Serie C No. 92.

Corte IDH (2003). Caso Myrna Mack Chang. Sentencia de noviembre 25 de 2003. Serie C No. 101. 
Galtung, Johan. (2003) Paz por medios pacíficos. Paz y conflicto, desarrollo y civilización, Bilbao, Gernika Gogoratuz.

Hayner, Priscilla (2008). Verdades inmemorables. México. Fondo de Cultura económica.

Maldonado, Carlos Eduardo. (2012). Significado e impacto de las ciencias de la complejidad.

http://www.carlosmaldonado.org/articulos/EL\%20PROBLEMA\%20DE\%20UNA\%2 0TEOR\%CDA\%20GENERAL\%20DE\%20LA\%20COMPLEJIDAD.pdf.

Núñez, Violeta (2007). Pedagogía social: un lugar para la educación frente a la asignación social de los destinos. Disponible en línea:

Peñuela, Alejandro y Álvarez, Luis Guillermo (2009). colectivo: implicaciones sociales. Una aproximación psicológica a las agendas de información. Disponible en línea: http://www.razonypalabra.org.mx/anteriores/n26/lpenuela.html

Sequeira, Leslie (2009). La recuperación de la memoria histórica y sus dilemas. Disponible en línea: http://www.irenees.net/bdf_fiche-analyse-943_es.html noviembre de 2013.

Vélez Cuartas, Gabriel (2011). El cambio en las redes: una aproximación a las relaciones sociales desde el lenguaje, la representación y la institucionalización. Disponible en línea: http://revista-redes.rediris.es/html-vol10/vol10_6.htm

Zuleta, Estanislao (1969). El elogio de la dificultad. Disponible en: http://www.elabedul.net/Articulos/el_elogio_de_la_dificultad.php 